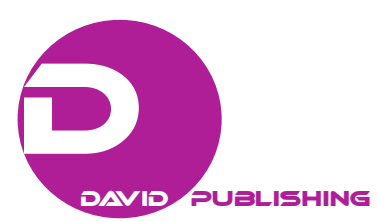

\title{
Sport in Adjara as a Tool of Tourist Attraction
}

\author{
Paata Chaganava, Tamar Beridze, Tsira Tsetskhladze \\ Shota Rustaveli State University, Batumi, Georgia
}

\begin{abstract}
The research aimed to identify the ways the sport could be used to attract the new visitors in the tourism destinations. Adjara Autonomous Republic located in Georgia, as one of the developed tourism regions of the country, was chosen as an object of the research. The theoretical schema that links the sport events to tourism was developed and the factors, related with the specifics of sport type, attractiveness, and financing, which restrain the usage of sport for tourist attraction, were identified on the first stage of research. The case of Adjara region authority financing and supporting the sport in the region was learned and discussed on the second stage of the research. Three approaches to the sport event, as a tourist attraction, were analysed on the third stage of the research: international sport events, fighting events, and traditional sport events. The positive and negative sides of each one were identified. As the research revealed, orientation on traditional and national sport events are mostly attractive for tourism policy measures, because the Adjara region could offer tourists the outstanding experience. The other side of this approach is the necessity of big investments for promotion of such sports.
\end{abstract}

Keywords: traditional sport events, Adjara, sport and tourism, Lakhti, Chidaoba, tourism specifics of sport

\section{Introduction}

The continuously rising competition on the international tourism market creates the necessity of new directions for destination tourism policy planners and makers to attract the tourists. Adjara Autonomous Republic, the touristic region located in the south-west part of Georgia on the Black Sea east shore, is the example of such a challenge. Although the region attracts more and more tourists yearly and there are new types of recreation and leisure developing in the area, one day the region could find itself on the peak of tourism area life cycle and face the decline started. Sport could be one of the solutions of perspective problems.

The given research aimed to define the readiness of Adjara, as a tourist destination, to transform the sport events into the tourist attractions. This aim contained the solution of two tasks: First of all, the sport's modern conditions in Adjara should be discussed; and second, the tourist demand structure on sport events in the region should be assessed.

The research was conducted in three stages. At first stage, the specifics of different types of sport were learned, keeping in mind that some characteristics could limit the usage of particular type of sport to attract tourist. Also, the theoretical schema that shows how the sport event is linked to tourism was elaborated.

Paata Chaganava, candidate, associate professor, Tourism Department, Shota Rustaveli State University, Batumi, Georgia.

Tamar Beridze, Dr., assistant professor, Hospitality Department, Shota Rustaveli State University, Batumi, Georgia.

Tsira Tsetskhladze, Dr., assistant professor, Tourism Department, Shota Rustaveli State University, Batumi, Georgia.

Correspondence concerning this article should be addressed to Paata Chaganava, 9 Sherif Khimshiashvili str., Batumi 6000 , Georgia. 
On the second stage, the facts and figures about how Adjara region authorities support sport events were discussed to reveal the readiness of the region to use sport as a tourist destination.

At the third stage of research, the three alternatives for using the sport as tourist attraction were discussed: (1) "big" international sport events, such as Olympic Games or championships; (2) fighting sport events; and (3) authentic and local sports. The negative and positive sides for each direction were studied.

\section{Sport Specifics and Limitations for Tourism}

The modern tourism business is least concentrated on sport events as the tools of attraction of tourists. There are several causes for that. First of all, in many cases, the sport event is not so attractive show to get the tourists massively. The Olympiads and Football World Cups are the exclusions, attracting huge number of sportsman and funs in tourism destination. Although the clear benefits of sport events for tourism, the effectiveness of public money spent could become the object of criticism in the long run. The examples for that are the Olympiads of Sochi and Rio de Janeiro - the huge useless Olympic infrastructure left. The Football World Cups could become the objects of such a criticism in a relatively less times, because the matches are arranged on the stadiums that are already used as a football arena during country championships during whole year, but the football is the biggest exclusion. In this list, the rugby, American football, baseball, basketball, boxing, and tennis could be included, but generally, from the dozens of sport types, including wrestling, the most preferable for all the Georgians, could not be counted as a tool of attracting tourists - it seems the problems lays in the lack of promotion-football, for example, is the strong industry, a bunch of private and public, national and international interests. It could be described, as an industry, clearly oriented on entertaining the fans, with great possibility to attract new "consumers", successful promotion of football personalities and strong advertisement infrastructure. The sphere is profitable without any tourism actions and in addition creates the benefits for tourism (Meladze, 2008; Gammon \& Robison, 2003; Mokras-Grabowska, 2016; Ramallal et al., 2010; Yildiz \& Çekic; 2015).

Second, the sportsmen and sports have some specific characteristics. Each type of sport is a kind of closed system and the sportsmen are the members of relatively limited circle, less oriented on the show. The specifics of sport often define that the process itself less or totally not contents the elements of the show. Of course, the contest is attractive by itself, but in many cases, the success could (and should) be reached by the non-attractive actions, that could not be called as show and be sold to tourists (Japharidze, 2016; Ross, 2001; Schwark, 2007).

The third is the specifics of financing. There is no possibility for each country to have enough quantity of "consumers" for each type of sport to ensure the profitability of private club operations and massive events or league-type contests. Some types of sport are more popular than the others. But the government should finance every types of Olympic sport, which means that the budget resources should be directed not only on the popular sports but for every type of Olympic sport types that may not be suitable for the specifics of country. The governments are obliged by the society to finance such types, if there is smallest quantity of citizens wish to follow these types of sport (Higham \& Hinch, 2009; Pinson, 2014).

More of that, the extreme sport, that is the tourism type by itself - the possibility to entertainment and recreation for traveler, is not a big segment on the tourism service market, for argue its important role on tourism destination economy.

Although the problems restrain the usage of sport in tourism destinations for raising the traveler flows, the sphere could be foreseen as an instrument of tourism development. 


\section{Support of Sport in Adjara}

First of all, the mechanism of using tourism for tourism development should be theoretically acknowledged. The mechanism is represented in Figure 1.

Figure 1 represents the sport event demand side, contained travelers, traveling to visit the sport event and sportsmen, visiting the destination to participate in contest. Both are consumers for tourist services.

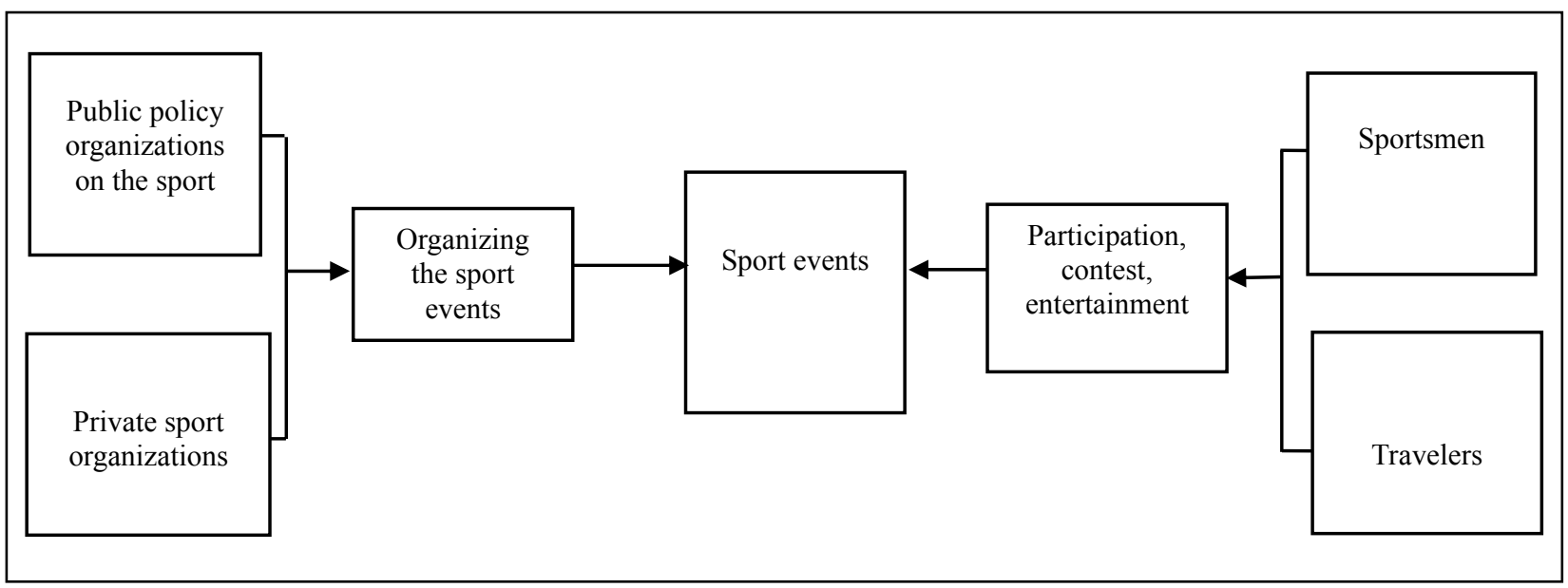

Figure 1. Sport events supply and demand sides.

Sport event supply side is represented by public and private organizations, which, separately or jointly organize the events.

Adjara is the autonomous republic of Georgia. The sport is under responsibility of local Ministry of Education, Culture, and Sport. The Ministry arranges a range of programs in sport. These programs are represented in Table 1.

Table 1

Financial Resources Assigned to Sport by the Ministry of Education, Culture, and Sport of Adjara Autonomous Republic (Thousand Lari)

\begin{tabular}{llllll}
\hline $\mathrm{N}$ & Program title & $\begin{array}{l}\text { Year 2015 } \\
\text { actual }\end{array}$ & $\begin{array}{l}\text { Year 2016 } \\
\text { actual }\end{array}$ & $\begin{array}{l}\text { Year 2017 } \\
\text { actual }\end{array}$ & $\begin{array}{l}\text { Year 2018 } \\
\text { planned }\end{array}$ \\
\hline $1 \quad$ Ministry budged total, including: & $35,755.7$ & $38,777.8$ & $44,079.4$ & $51,578.4$ \\
1.1. & Sport development support in schools & 331.6 & 519.4 & 376.9 & 0.0 \\
1.2. Non-school sport educational organization support, including: & $1,531.7$ & $1,391.2$ & $1,424.4$ & $1,410.0$ \\
1.2.1. LEPL "Batumi Sport School" & $1,285.4$ & $1,151.7$ & $1,129.8$ & $1,200.7$ \\
1.2.2. LEPL "Batumi Tennis Complex" & 246.3 & 239.4 & 294.6 & 209.3 \\
1.3. Support and popularization of sport and strengthen the youth & $3,139.7$ & $3,019.4$ & $3,819.3$ & $4,341.1$ \\
affairs, including: & 419.1 & 414.5 & 412.6 & 457.8 \\
1.3.1. Management of sport and youth affairs & $2,311.9$ & $2,384.6$ & $3,060.3$ & $3,491.0$ \\
1.4. Support of sport, including: & $1,264.7$ & $1,239.2$ & $1,351.8$ & $1,335.0$ \\
1.4.1. Sport events & 366.8 & 364.5 & 390.5 & 375.5 \\
1.4.2. One-time monetary prizes for success reached by Adjara teams" & members, general and individual coaches & 420.5 & 649.7 & 773.5 & 811.0 \\
1.4.3. Support of group and individual types of sport & & 0.0 & 0.0 & 0.0 \\
1.4.4. Preparation of Adjara sport teams for "Youth Olympic Festival & 154.7 & 0.0 & \\
\hline
\end{tabular}


(Table 1 continued)

\begin{tabular}{|c|c|c|c|c|}
\hline 1.4.5. Social support and incentive for coaches, referees, and sportsmen & 105.1 & 131.2 & 144.5 & 169.5 \\
\hline 1.4.6. Procurement of sport inventory & 0.0 & 0.0 & 0.0 & 800.0 \\
\hline 1.5. Support of 2018 year world chess Olympics, including: & 83.0 & 584.1 & 805.7 & $2,012.0$ \\
\hline $\begin{array}{l}\text { 1.5.1. LEPL } 2018 \text { Year World Chess Olympics Organizational } \\
\text { Committee }\end{array}$ & 70.8 & 149.1 & 160.5 & 282.0 \\
\hline 1.5.2. Support the preparation for 2018 Year World Chess Olympics & 12.2 & 435.0 & 645.2 & $1,730.0$ \\
\hline
\end{tabular}

Source: 2018 year budget of Adjara Autonomous Republic.

The budget of local Ministry of Education, Culture, and Sport is spent on different sport events, such as the supporting the World Chess Olympic Games of 2018. It shows that the local government acknowledges the importance of sport events for region. It also shows that the Adjara region has an experience in the sphere of organizing sport events. Both factors affecting the region's ability, host the important sport events which have tourist effect. In addition, in the nearest future, there are important infrastructure plans to be implemented which could raise the sport facilities of the region-building of new football arena and new sport complex. It is supposed that these objects, in parallel with hosting the sport events, will be the tourist attractions by itself.

\section{Three Approaches to the Sport Events as Tourist Attractions}

The demand on sport shows from the tourist side also should be discussed. It means that the "products" should be defined, which the tourist business could offer the tourists. Three approaches to the sport event, as a tourist attraction, could be developed: international sport events, fighting events, and traditional sport events. These approaches are charted in Figure 2.

As it is shown in Figure 2, all the three approaches have their positive and negative sides. If the policy-makers choose the international sport events, it could cost them a much of taxpayers resources, but also ensure the huge number of tourists visiting the destination and being served. The colossal infrastructural investments in big sport event create a threat that in the long run, these facilities will be unloaded and unbeneficial to society.

Fighting events could be also attractive for tourism policy-makers, because in this case, the region could find its niche as a destination where such a fight contests take place and it could be used as key theme for promotion campaign to attract a special type of travelers, but this way of tourism development has its own negative side related to criminal — underground gambling industry.

Orientation on traditional national sport events is mostly attractive for tourism policy-makers, because the destination could offer tourists the outstanding experience. It could be the national group or individual contest, traditional, modern, or even invented/developed one, that has elements of the show and could be packed as tourist experience, meeting his/her demands as an attendant or participant.

There are at least two Georgian national traditional contests that have such a potential. The first one is Georgian wrestling "Chidaoba" - the traditional individual martial art characterized with its own system of dodges and ritualized process of contest. The second one is Georgian group contest "Lakhti" - kind of castle defence simulation game, which is so matched to Georgian character and Georgian endless war history that every Georgian boy should participate in it at least once in his lifetime. Correctly organized, such national sports or games could become the profit-generating attractions. The other side of this approach is the necessity of big investments for promotion of such sports. 
Anyway, from today's point of view, most attractive could be the third approach. There is one important argument for this - modern tourism market is characterized by huge and growing number of destinations. The winner of competition could be only the destination that offers the unique experience to traveler. National traditional sport events might be such an experience.

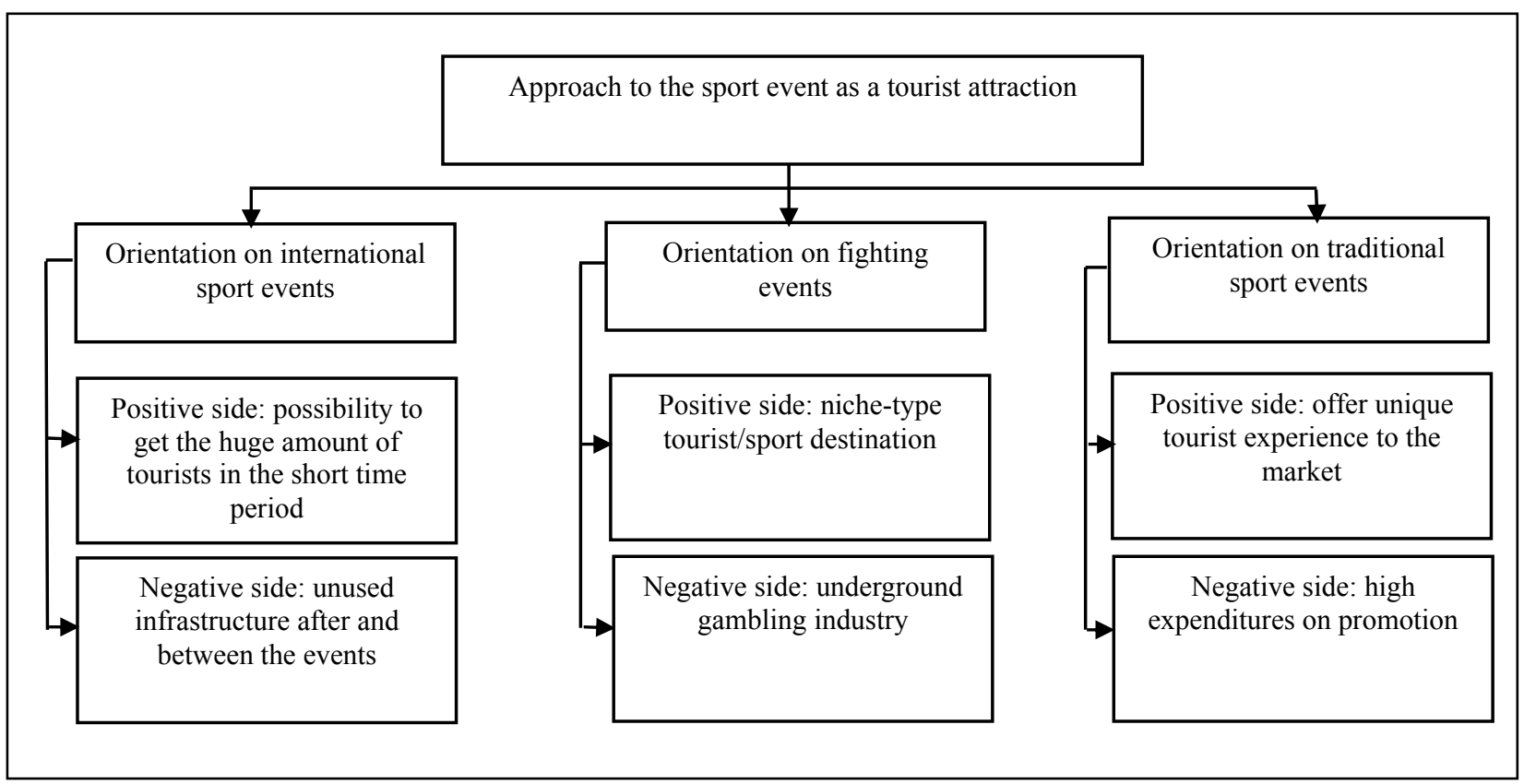

Figure 2. Approaches to the sport event as a tourist attraction.

\section{Conclusions}

The research revealed that in many cases, the sport event is not presented in the form of such a show that attracts tourists massively. More of that, some types of sport and specifics of contest do not mean the presentable and show-like actions. The state/local budget limitations also restrain the development of the sport events into tourist attractions.

The readiness of authorities plays key role in such transformation processes. The study of Adjara Autonomous Republic case reveals that the budget for sport of the local Ministry of Education, Culture, and Sport is rising from year to year and Ministry has an experience to support such a sport events, e.g., World Chess Olympic Games of 2018. It means that there are both financial and experiential conditions to make government ready to transform such events into the tourist attractions.

The orientation on the national, local, and authentic types of sport to develop them as a tourist attraction could be considered as optimal instrument, because it gives tour-operators the possibility to offer the unique tours and the tourism policy planners and makers to arrange an effective tourism promotional campaign. Such an approach is also sustainable-type approach, because it preserves the cultural heritage of the area/country.

\section{References}

Gammon, S., \& Robison, T. (2003). Sport and tourism: A conceptual framework. Journal of Sport and Tourism, 8(1), 21-26.

Higham, J., \& Hinch, T. (2009). Sport and tourism: Globalization, mobility and identity. Oxford: Elsevier Butterworth-Heinemann.

Japharidze, Z. (2016). Diplomacy aspects of international sport (Doctor's dissertation, Georgian Technical University, Tbilisi). 
Meladze, M. (2008). Tourist product formation specifics in Georgia (Doctor's dissertation, Ivane Javakhishvili Tbilisi State University, Tbilisi).

Mokras-Grabowska, J. (2016). Sports tourism: Terminological discussion. Tourism, 26(1), 13-18.

Pinson, J. (2014). Heritage sporting event: An old recipe for a new problem. Heritage, Tourism and Hospitality International Conference, 6-8 November, Istanbul, Turkey.

Ramallal, G., Eduardo, M., Rodríguez, M., Rosa, J., Turégano, S., \& Ángel, M. (2010). Sport and tourism: A potentially conflictual relationship. Revista de Turismo y Patrimonio Cultural, 8(2), 265-276.

Ross, S. D. (2001). Developing sports tourism: An e-guide for destination marketers and sports events planners. National Laboratory for Tourism and e-Commerce, University of Illinois at Urbana-Champaign, France.

Schwark, J. (2007). Sport tourism: Introduction and overview. European Journal for Sport and Society, 4(2), 117-132.

Yildiz, Z., \& Çekic, S. (2015). Sport tourism and its history and contribution of Olympic Games to touristic promotion. International Journal of Science Culture and Sport (IntJSCS), 4(Special Issue), 326-337. 